\title{
Reflecting on Learner Assessments and Their Validity in the Presence of Emerging Evidence from Neuroscience
}

\author{
Chandana Watagodakumbura ${ }^{1}$ \\ ${ }^{1}$ Faculty of Information Technology, Monash University, Melbourne, Australia \\ Correspondence: Chandana Watagodakumbura, Faculty of Information Technology, Monash University, \\ Melbourne, Australia. Tel: 61-393-081-779. E-mail: chandana.watagodakumbura@monash.edu
}

Received: February 25, 2015

Accepted: April 14, 2015

Online Published: May 25, 2015

doi:10.5539/hes.v5n3p58

URL: http://dx.doi.org/10.5539/hes.v5n3p58

\begin{abstract}
We can now get purposefully directed in the way we assess our learners in light of the emergence of evidence from the field of neuroscience. Why higher-order learning or abstract concepts need to be the focus in assessment is elaborated using the knowledge of semantic and episodic memories. With most of our learning identified to be implicit, why we should make use of the constructivist theory in assessing learners becomes quite evident. Why we need to deviate from setting assessment on the basis of veridical decision making and the need incline towards adaptive decision making become evident when we understand that most of our life decisions are adaptive in nature and human beings naturally possess creative instincts. When assessments are used to direct learners to use the frontal lobes, the organ of civilisation, more, the requirement of more carefully designing the timing component of assessment arises. After all, it is important to understand that enhancing learner consciousness and wisdom is key when we understand the prime goal of education is to enhance human development of learners so as to enable them to be better problem solvers.
\end{abstract}

Keywords: assessment, neuroscience, higher-order learning, semantic memory, consciousness, human development

\section{Introduction}

This paper is organised into two main parts: the first part introduces neuroscience-based concepts that relates to assessment while the second part explains how newly emerging neuroscience-based concepts can be used in setting up assessments appropriately, improving their validity. The need for assessments to focus on abstract concepts and higher-order learning and how these phenomena relate to semantic memory is discussed first in the second section. A discussion on the significance of taking into consideration the constructivist theory and predominant implicit learning in constructing assessment is presented next. Then we elaborate on the need for assessment to focus on adaptive decision making ahead of veridical decision making. A section on the significance of timing factor in assessments that necessarily direct users to use the frontal cortex is followed finally by a discussion on the need to set assessments in a manner that they direct learners to enhance consciousness and wisdom.

\section{Introduction to Neuroscience-Based Concepts that Relate to Learner Assessment}

\subsection{Basic Structure of the Human Brain (Baars \& Gage, 2010)}

Mainly there are 3 layers in the human brain, from bottom to top: the reptilian brain, mammalian brain and neocortex. The reptilian brain is the oldest layer of the brain; it is composed of the brain stem, the structures that dominate in the brains of snakes and lizards. This part of the brain controls survival activities such as breathing, hart rate and balance. The mammalian brain is layered over the reptilian brain and consists of a system of brain parts called the limbic system. The constituents of the limbic system include amygdala, hippocampus and hypothalamus. The limbic system plays a major role in human emotions. The 3rd layer of the brain is the neocortex or primate brain which is the most recent addition to our brain. It consists of wrinkled covering of cerebral hemispheres - left and right. The neocortex plays a major role in cognitive, linguistic, motor, sensory and social abilities. It gives considerable flexibility in creativity in adapting to changing environments. The neocortex is densely interconnected with the limbic system and controls the expression of emotions.

The neocortex has 4 major lobes, namely, the frontal lobe, parietal lobe, temporal lobe and occipital lobe. One 
significant feature of the brain structure is brain localisation. That is, the brain is composed of a large number of functionally specialised regions. There are about 100 Brodman areas, so to speak, now recognised in the neocortex. The 4 lobes of the neocortex and their processes are intricately intertwined with each other. Further, the neocortex, which is vital for cognitive functions, interacts constantly with major so called satellite organs such as the thalamus, basal ganglia, cerebellum, hippocampus and limbic regions.

It is of special interest to know that frontal lobes are referred to as the organ of civilisation. The role the frontal lobes play in cognition is uniquely human and without their development civilisation could never have arisen. They are crucial for all higher-order purposeful behaviours such as identifying the objective, projecting the goal, forging plans to reach it, organising the means by which such plans can be carried out and monitoring and judging the consequences. Further, frontal parts of the brain become active when resolving conflicting conditions. A correlation has also been identified between frontal activation and longer reaction time and sense of subjective effort. In summary, the frontal lobe, or more specifically the pre-frontal cortex (PFC), is used for human activities such as language, thought and executive control of higher-order processes and connect directly with every distinct functional unit of the brain. This connectivity allows PFC to coordinate and integrate the functions of other brain structures.

\subsection{Types of Memory (Baars \& Gage, 2010)}

Human memory can be defined as a lasting representation that is reflected in thought, experience, and/or behaviour. It can be divided into 2 main types: explicit and implicit. Explicit memory refers to the memory with conscious awareness and the individual can declare its existence and comment on its content either verbally or non-verbally. Consequently, such memories are known as declarative memories. On the other hand, implicit memory is not accompanied by conscious awareness that one has a memory; the existence of implicit memory is inferred only from the effects it has on behaviour. Further, implicit memories may be retrieved without an intention to remember and accessed commonly by priming tasks.

Explicit or declarative memory can be further divided into 2 types: episodic (autobiographical) memory and semantic memory. Episodic memory refers to memories that have a specific source in time, space and life circumstances. In contrast, semantic memories involve facts (or high-level concepts and generalisations) about us, the world, and other knowledge that we share within a community and are independent of the spatial and temporal context in which they were acquired. Further, episodic memories are remembered consciously and susceptible to forgetting while semantic memories give a feeling of knowing rather than a fully conscious recollection and less susceptible to forgetting. Initially memories are episodic and context dependent and over time they are transformed into semantic memories.

\subsection{Types of Learning from the Viewpoint of Neuroscience (Baars \& Gage, 2010)}

Learning can be defined as the acquisition of lasting representations that involve a wide range of brain areas and activities. Very often, the unstated goal of learning is to turn explicit problem solving into the implicit kind. Similar to the way we discussed about explicit and implicit memories, learning can also be explicit or implicit. Explicit or declarative learning involves conscious learning while implicit (unconscious) learning results as a side effect of conscious input. That is, even for implicit learning, conscious events guide the learning process. But there is no exclusively conscious learning as both, conscious and unconscious, processes always go together. In a complete learning cycle, 3 phases can be identified: learning, retention and retrieval. Retention is generally viewed as unconscious, although it is shaped by conscious experiences. Explicit learning generally occurs when we pay attention to new information so that it becomes conscious. The brain begins learning as soon as it is placed in any novel environment. Simple novelty is enough to trigger attention and learning, including significant evoked potentials that sweep through the entire cortex. As soon as we experience or understand the new information with enough clarity, our brains are able to store it. Sometime it may require repeated attention new or difficult information in order for us to get a sense of clarity. Any new material may seem vague or hard to understand at first; however, when we spend time thinking about it or paying attention to it, a clearer sense of meaning tends to appear.

Brain takes more time to solve novel problems and voluntary actions become automatic with practice. As they do so, we tend to lose executive control over them. Cortical activity reduces when predictable voluntary action is practiced to the point of automaticity. Once even very complex processes are learned, they seem to require less cortical activity.

Most of our learning is identified to be incidental, meaning that it occurs as a result of paying attention and becoming conscious of. That is, we do not deliberately memorise things all the time; memorising is only one way to make learning happen. 
With our current practices, academic learning is mostly explicit with teachers pointing out the things to be learned and students doing their best to memorise them. However, most ordinary human learning is implicit. For example, social habits and language are mostly leant implicitly. Looking from another perspective, most knowledge is tacit knowledge and most learning takes place implicitly before it can be stated explicitly. Further, academic exams usually test associative recall (What is the capital of Australia?) rather than recognition tests. Associative recall tests give much lower estimates for accurate memories than recognition tests. That is, in associative recall, we expect more exact and specific answers than in recognition tests. Interestingly, these exact and specific answers are the ones that are likely to be forgotten soon.

Hebbian learning, named after neuropsychologist Donald Hebb, is summarised to "neurons that fire together wire together". It indicates that the more frequent certain synaptic connections are made the more likely they are to form lasting neural networks. In other words, synaptic connections that are rarely used will eventually die out (Diamond, 1996, 2001). This is a very simple idea on how we can explain the way learning takes place. In fact, it is observed that forming new synaptic connections or synaptogenesis takes place throughout one's lifespan, enabling a lifelong learning process. In other words, cortical plasticity lasts throughout the lifespan of a human being. However, in a changing, dynamic world, unlearning also has an important role to play. That is, we will have to let misconceptions or inaccurate knowledge to die out from our neural system. Further, human brains are identified to be selectionist rather than being instructionist, meaning that synaptic connections can grow by selecting new connections, not merely being restricted by an existing limited set of instructions as that happens in computers. In other words, human brains can be creative by learning new knowledge in the form of new synaptic connections that did not exist before.

\subsection{Consciousness from the Viewpoint of Neuroscience (Baars \& Gage, 2010)}

Scientists have confirmed that consciousness can be defined and studied scientifically, contrary to the beliefs held previously. Consciousness results from neuronal interaction between thalamocortical systems; the neocortex is the main organ involved in it. The evolution of consciousness is understood to be the highest expression of the developed brain that parallels the evolution of the prefrontal cortex (PFC). Synonyms used for consciousness are awareness, explicit cognition and focal attention. Consciousness can be identified mainly in two levels - primary and higher-order consciousness. The former is concerned with perceptual world while the latter is related to abstractions and thought. Further consciousness involves with a range of contents: sensory perception, visual imagery, emotional feelings, inner speech, abstract concepts and action related ideas indicating the involvement of a number of brain regions, through an integrative view. Of special interest is the theory developed by Giulio Tononi in the name of Integrated Theory of Consciousness. It provides a new way to study consciousness using a rigorous scientific approach. Integrated theory of consciousness is a framework that is built on the notion that consciousness is a consequence of systems that have both a large amount of differentiated information that is also highly integrated. To summarise the idea, a computer may have a large quantity of memory (say $16 \mathrm{~GB}$ ), but since these memory pieces are not integrated, computers do not have consciousness. Scientists have also been able to quantify the level of consciousness with a measure called neural complexity (C). High values of $\mathrm{C}$ characterise conscious events and reflects the extent to which the dynamics of a neural system are both integrated and differentiated. Consciousness in humans can also be understood with the cognitive architecture known as Global Workspace Theory (GWT). GWT proposes that momentarily dominant information is widely distributed in the brain. That is, the nervous system can be viewed as a massive distributed set of special-purpose networks. Consequently, coordination, control, and novel problem solving could take place by way of central information exchange. Conscious involvement of brain resources is particularly useful when novel information needs to be combined and integrated.

\subsection{Automaticity from the Viewpoint of Neuroscience (Baars \& Gage, 2010)}

In general, the more predictable a sensorimotor skill becomes, the less of it will become conscious. The fading of conscious access to habitual skills is commonly called "automaticity" and it goes along with a loss of precise voluntary control over habitual details. Repetitive events tend to fade from consciousness unless they have special significance. That is, voluntary actions we are conscious with become automatic with practice. As they do so, we tend to lose executive control over them. In other words, effortful tasks show a wider spread of brain activity; the brain takes more time to solve novel problems and switching from one task to another seems to require additional mental resources beyond those involved in routine and automatic actions. The level of activity in cortex (at least) drops with practice and automaticity. It seems to indicate the recruitment of neuronal resources that are needed to work together to perform a task that is new or unpredictable. 


\subsection{Goals of Education from the Viewpoint of Neuroscience (Baars \& Gage, 2010)}

Very often, the unstated goal of learning is to turn explicit problem solving into the implicit kind. Explicit problem solving has clear conscious goals and clearly defined steps, greater executive control, higher mental workload, wider recruitment of cortical regions. Implicit problem solving is, however, more common and will become more proficient, implicit (unconscious) and automatic with practice. It uses less executive control, has less cortical involvement and is more dependent on long-term memory and highly practiced routines.

As a part of goals of education, individuals also need to become better decision makers through education. In schools or colleges, we are usually given a problem or question and we must find or write the correct answer. Usually only one correct answer exists to these questions or problems. For example, balancing a check book and remembering the capital city of a country are similar tasks. By finding the correct solution, we engage in veridical decision-making. However, apart from high school exams, college tests and factual and computational trivia, most decisions we make in our everyday lives do not have intrinsically correct solutions. That is, the decisions we make are not always objective, rather they are, in most cases, subjective. What career path to make, what location to visit in the vacation are some such example decisions we make in ambiguous situations. By making a decision or choice, we engage in adaptive decision-making. Further, our best neural system performance is not for the exact symbol sequences that conventional computers handle so well. Rather, our brains are exceptionally good at dealing with complex, ill-defined, and novel challenges, the kinds that people have to deal with in the real world. That is, humans are exceptionally flexible in adapting to new conditions. The choices we make are not inherent in the situations at hand. There are complex interplay between the properties of the situations and our own individual properties, aspirations, doubts, and histories. The Prefrontal Cortex (PFC) is central to such decision-making or evaluation. Finding solutions for deterministic situations often is accomplished algorithmically or following a number of steps routinely. These tasks are increasingly delegated to various devices such as calculators, computers and the like. However, making judgments, in the absence of inherently correct solutions, remain, at least for now, a uniquely human territory. Thus, through education an individual must develop the capacity to have the flexibility to adopt different perspectives on the same situation at different times. The organism must be able to disambiguate the same situation in multiple different ways and to have the capacity to switch between them at will. Frontal lobes of the brain hemispheres play an important role in dealing with these ambiguous situations.

\section{Use of Emerging Evidence from Neuroscience in Formulating Assessments}

\subsection{Assessing Concepts/Higher Order Learning and How They Relate to Semantic/Episodic Memories}

We as educators have a general understanding that assessment should test higher-order learning. The term higher-order learning relates well to the hierarchy of levels described in Blooms Taxonomy (Biggs, 2003; Entwistle, 1998), a popular tool among educators used for classifying the quality of learning. In Bloom's taxonomy, we have evaluation and synthesis at higher levels while comprehension and knowledge are at lower levels; analysis and application processes are found at the middle. When we refer to assessing higher-order learning, we essentially want to assess our learners for their ability to synthesise and evaluate. Looking at this from another perspective, we want our learners to demonstrate their understanding of underlying abstract concepts. To reiterate, in Kolb's experiential learning cycle (Kolb, 1983), abstract conceptualisation is considered as the most important stage (Watagodakumbura, 2013; Zull, 2002). This premise of ours can now be validated from the evidence available in neuroscience. Our high-level knowledge or concepts are stored in our brains as semantic memory that lasts longer. On the other hand more specific details pertaining to certain situations are stored as episodic memory and are more susceptible to forgetting quickly (Baars \& Gage, 2010). Further, episodic memory is associated with sources of time and space while semantic memories are independent of sources of time and space. Now we see that high level concepts are generalised summaries of knowledge or facts that are valid beyond the time and space of occurring. Consequently, in assessments, it is justified that we test learners understanding of these concepts associated with semantic memory ahead of more specific details associated with traces of episodic memory that are valid for a specific time and space. In addition, generalised concepts have the capacity to penetrate into other domains of knowledge and application so that a deeper understanding (Paul \& Elder, 2000) of them has a more lasting value into the future.

\subsection{Assessment Taking Constructivism and Implicit Learning into Consideration}

The constructivist theory of learning (Biggs, 2003) indicates that during a teaching-learning process, every learner creates knowledge internally and independently. That is, every learner creates subjective knowledge based on his existing knowledge base. From the point of view of neuroscience, when new knowledge is created internally, learners create new neural networks and associate them with the existing neural networks. We clearly 
understand 2 important points here; that is knowledge is subjective (Yero, 2002) as opposed to being objective and that learning has a physical meaning, which indicates the growth of neurones to make more connected networks (Diamond, 1996, 2001; Zull, 2002). Further, evidence from neuroscience shows that most of our learning as human beings are implicit (Baars \& Gage, 2010). In academic environments, we mostly have explicit learning in which the teacher tells learners what to learn and try to get brain resources focused on the particular task being learned. On the other hand, implicit learning takes place unconscious to the learner and does not have to take place in an academic or teaching-learning environment. Another related term we use is incidental learning (B. Eide \& Eide, 2004) in which human beings learn implicitly by observing an incident or undergoing a situation. Now, we see an interesting relationship between constructivism and implicit learning. Since learners make subjective knowledge internally and individually and most of our learning is implicit, in assessments, we as educators have to accommodate learners to provide their subjective responses, followed by assessment for their validity. That is, we have to be mindful that even in a formal teaching-learning environment, learners can learn certain things implicitly depending on their background and engagement level. Put differently, learners may create new knowledge that the teacher may not have implied or given out directly. Considering this situation, asking objective type questions where there is one correct answer will not encourage our learners to be creative and unique in providing their responses; it does not allow us to evaluate learners on the level of higher-order learning achieved. Rather, it promotes a rote learning environment in which learners tend to commit facts into short-term memory in preparation for assessment tasks. In summary, we have to set assessment in a manner that allows learners to respond subjectively as well as to demonstrate their implicit learning which should then be evaluated for the level of higher-order learning demonstrated. Theses assessments contrasts from the ones that prompt learners to merely reproduce specific facts memorised. It is also worth noticing that gifted learners (Silverman, 1998, 2002) are highly capable in incidental or implicit learning (B. Eide \& Eide, 2004), and they will not be disadvantaged, as that happens in traditional classrooms, if assessments are set in the above mentioned manner. In addition, providing a better learning environment for gifted individuals, who demonstrate a higher level of overexcitable characteristics (Dabrowski, 1970, 1972, 1977), we can be more inclusive (Goleman, 2005; Webb, 2005, 2008) in our pedagogical practices, within a neurodiverse (Armstrong, 2011; Watagodakumbura, 2013) society.

\subsection{Assessment Encouraging Adaptive Decision Making Ahead of Veridical Decision Making}

We have seen that learners construct subjective meaning from what they learn and most of the learning is implicit, unconscious to the learner and may not have been implied by the teacher. Further, we have recognised that higher-order learning or high level concepts last longer in learners' minds, are more useful in general and are not valid restrictively for sources of limited time and space. In the presence of these evidences, the challenge now is to identify ways to construct assessments appropriately yielding validity. We have to note that human brains are selectionist unlike typical computers which are instructionists (Baars \& Gage, 2010). That is, computers are relying on a limited set of symbols to identify a predefined solution while human brains can produce new solutions by creating new neural networks that did not exist before. That is why human beings are identified be creative while computers are not (Beale \& Jackson, 1990). Put differently, human beings are better in adaptive decision making while computers are better in veridical decision making. Answers we expect will not have one right answer, rather the answer will be dependent on the way learners have argued or evaluated to make a valid judgment on a somewhat ambiguous situation. In most of our life situations, we make adaptive decisions in the presence of ambiguous conditions. Now we have a clue on how we have to direct our assessment components. We have to give learners the opportunity to provide creative and individualised responses and then evaluate them for quality and validity. In other words, we have to design and ask open-ended or subjective type questions instead of objective type questions from our learners. Further, these questions have to be based on testing the understanding of abstract concepts rather than specific details. We are essentially avoiding here associative recall type questions and incline towards recognition tests. In the former type, reproduction of exact memorised facts is done while in the latter, awareness or understanding of a high-level concept is demonstrated.

\subsection{Giving Consideration to Time Factor in Assessments When Individualised, Unique Answers are Expected Essentially Utilising Frontal Cortex instead of Succumbing to Automaticity}

We now understand that most of the decisions we make in day-to-day life situations are adaptive in nature. There are no strict procedures or predefined routine actions to carry out until one specific answer is obtained, as in the case of veridical decision making. In adaptive decision making in the presence of ambiguous conditions, frontal cortex of our brain gets involved extensively, resulting more executive control (Baars \& Gage, 2010). When frontal cortex gets involved in decision making, it takes relatively longer time. When we get involved in routine activities for a longer time, such as in habituation, the phenomenon known as automaticity results; when this 
happens voluntary actions become automatic and less cortical resources are used for the underlying process. Consequently time required to complete a routine task becomes relatively less. Now we can apply this timing concept to ours assessments. As highlighted before, we need to set our assessments in a manner that learners have to provide individualised, unique answers after making evaluations and a judgement on a somewhat ambiguous situation during the process. This process essentially utilises the frontal cortex and requires relatively longer time. We should not set our assessments in a manner that learners are only required to regurgitate premeditated or practiced answers quickly; learners are required to provide novel answers to reasonably novel questions we set. When answers are provided to novel questions, cortical resources are utilised better and avoids the situation of automaticity (Baars \& Gage, 2010). Considering this situation, we as educators have the responsibility provide adequate time for learners, to construct their subjective answers to open-ended questions we set and also to write them back on the paper; a sound judgement from us, the educators, is essential on this assessment timing matter (Watagodakumbura, 2013).

\subsection{Assessments Evaluating Understanding of Abstract Concepts Help Penetrating into Multiple Domains Thus Enhancing Learner Consciousness and Wisdom}

We as educators have understood the need for us to set assessments to test understanding of abstract concepts. Since abstract concepts are summaries of generalised knowledge, they have the power of penetrating into many domain areas and applications or in other words, utilise multiple intelligences (Gardner, 2006). That is, a single abstract concept has the propensity to be utilised in a number of applications across multiple domains. Since our brain consists of a large number of differentiated functional areas, it is highly likely that knowledge pertaining to different domains is stored in different regions of the brain. Consequently, when we focus on understanding of abstract concepts in assessment, we encourage learners to use multiple brain regions or functional areas to provide responses. When this happens, learners are directed to use their frontal cortex more elaborately. Further, when we set our assessments in a manner that learners have to answer open-ended questions with somewhat ambiguous conditions, the frontal cortex gets involved essentially. Consciousness is the phenomenon that multiple differentiated brain areas and functions are integrated and evolution of consciousness is considered as the highest expression of human development (Baars \& Gage, 2010). Similarly when we integrate knowledge of multiple domains areas to make useful inferences, we develop wisdom (Claxton, 2008). The frontal lobe, which is recognised as the organ of civilisation, plays a significant role in enhancing consciousness and wisdom. That is, we have to direct our learners to use frontal cortex as much as possible through our assessment activities. As a result, when we as educators set our assessments focusing understanding of abstract concepts and ask open-ended questions for learners to thrive, we are directing our learners to enhance consciousness and develop wisdom, which is also considered as a higher form of creativity. That is, we put learners on a path to a higher level of human development or self-actualisation (Maslow, 1968, 1993; Dabrowski, 1970, 1977) so that they could see reality better and become better problem solvers.

\section{Conclusion}

We have been constantly getting updated information from the evolving field of neuroscience. Many educators are making attempts to use evidence from neuroscience in teaching-learning activities. In this paper, we have discussed a number of related concepts and practices we can utilise in assessments in order to improve the validity of our assessment tasks. Mainly, we have identified that assessments need to test understanding of abstract concepts and this understanding need to be evaluated using relatively open-ended questions. Such practices allow learners to provide individualised, subjective responses within the constraints of broader knowledge base introduced. When learners are encouraged to provide their unique answers, we essentially give consideration to implicit learning, which is a major component of the learning process. When abstract concepts are the main focus of assessment, we are trying to access long-term memory traces of learners in the form of semantic memory and also to reach out information related to multiple domains that are likely to be stored in multiple brain regions or functional areas. Further, using open-ended, conceptual questions, we encourage learners to use frontal lobes of the brain, which is known as the organ of civilisation, elaborately. In providing answers, when frontal lobes are used to integrate knowledge from multiple differentiated brain areas, we direct learners to enhance their consciousness and wisdom. The significance of this approach can be better understood when we reflect on the fact that evolution of consciousness is considered as the expression of highest level of human development. Thus, aligning assessment in the discussed manner, we direct learners on a higher human development path, enabling them to see reality better and become better problem solvers in general. 


\section{References}

Armstrong, T. (2011). The Power of Neurodiversity: Unleashing the Advantages of Your Differently Wired Brain. Da Capo Lifelong Books.

Baars, B. J., \& Gage, N. M. (2010). Cognition, Brain, and Consciousness-Introduction to Cognitive Neuroscience (2nd ed.). Elsevier, MA: USA.

Beale, R., \& Jackson, T. (1990). Neural Computing-An Introduction. Institute of Physics Publishing. http://dx.doi.org/10.1887/0852742622

Biggs, J. (2003). Teaching for Quality Learning at University (2nd ed.). Buckingham, Society for Research into Higher Education and Open University Press.

Claxton, G. (2008). Wisdom: Advanced Creativity? In A. Craft, H. Gardner, \& G. Claxton (Eds.), Creativity, Wisdom and Trusteeship: Exploring the Role of Education. Thousand Oaks, CA: Corwin Press.

Dabrowski, K. (1972). Psychoneuroses Is Not An Illness. London: Gryf Publications.

Dabrowski, K. (1977). Theory of Levels of Emotional Development (Vol 1)-Multilevelness and Positive Disintegration. New York: Dabor Science Publications.

Dabrowski, K., Kawczak, A., \& Piechowski, M. M. (1970). Mental Growth through Positive Disintegration. London: Gryf Publications.

Diamond, M. C. (1996). The Brain... Use it or Lose It. New Horizons for Learning: School of Education, Johns Hopkins University. Retrieved from http://education.jhu.edu/newhorizons/Neurosciences/articles/

Diamond, M. C. (2001). Response of the Brain to Enrichment. New Horizons for Learning: School of Education, Johns Hopkins University. http://dx.doi.org/10.1016/B0-08-043076-7/03626-3

Eide, B., \& Eide, F. (2004). Brains on Fire: The Multimodality of Gifted Thinkers. New Horizons for Learning: School of Education, Johns Hopkins University. Retrieved from http://education.jhu.edu/PD/newhorizons/ Neurosciences/articles/

Entwistle, N. J. (1998). Approaches to Learning and Forms of Understanding. In B. Dart, \& G. Boulton-Lewis (Eds.), Teaching and Learning in Higher Education (pp. 72-101). Melbourne, Australia: Australian Council for Educational Research.

Gardner, H. (2006). Multiple Intelligences: New Horizons. New York: Basic Books.

Goleman, D. (2005). Emotional Intelligence. New York: Bantam Books.

Kolb, D. (1983). Experiential Learning: Experience as the Source of Learning and Development. Upper Saddle River, NJ: Prentice Hall.

Maslow, A. (1968). Toward a Psychology of Being. New York: Van Nostrand Reinhold.

Maslow, A. (1993). Farther Reaches of Human Nature. New York, N.Y., U.S.A.: Arkana.

Paul, R., \& Elder, L. (2000). Critical Thinking-Tools for Taking Charge of Your Learning and Your Life. Pearson Education.

Silverman, L. K. (1998). Personality and Learning Styles of Gifted Children. In V. Tassel (Ed.), Excellence In Educating Gifted \& Talented Learners (3rd ed.). Baska, Denver, Colorado, USA: Love Publishing Company.

Silverman, L. K. (2002). Upside-Down Brilliance: The Visual-Spatial Learner. Denver: DeLeon Publishing.

Watagodakumbura, C. (2013b). Education from a Deeper and Multidisciplinary Perspective-To a Sustainable Development of a Neurodiverse Society - A Futuristic View. Xlibris.

Webb, J. T. (2008). Dabrowski's Theory and Existential Depression in Gifted Children and Adults. Paper presented at the Eighth International Congress of the Institute for Positive Disintegration in Human Development, August 7-9, Alberta, Canada.

Webb, J. T., Amend, E. R., Webb, N. E., Goerss, J., Beljan, P., \& Olenchak, F. R. (2005). Misdiagnosis and Dual Diagnoses of Gifted Children and Adults: ADHD, Bipolar, Ocd, Asperger's, Depression, and Other Disorders. Great Potential Press.

Yero, J. (2002). How Teacher Thinking Shapes Education. New Horizons for Learning: School of Education, Johns Hopkins University. Retrieved from http://education.jhu.edu/PD/newhorizons/Neurosciences/articles/ 
Zull, J. E. (2002). The Art of Changing the Brain: Enriching the Practice of Teaching by Exploring the Biology of Learning. Stylus Publishing.

\section{Copyrights}

Copyright for this article is retained by the author(s), with first publication rights granted to the journal.

This is an open-access article distributed under the terms and conditions of the Creative Commons Attribution license (http://creativecommons.org/licenses/by/3.0/). 